\title{
APPLICATION OF ULTRASOUND ASSISTED EXTRACTION IN THE MANGIFERIN OBTAINING FROM Mangifera indica $L$ LEAVES
}

\author{
I. SEVILLA ${ }^{1}$, S. SALOMON ${ }^{2}$, I. AYALA ${ }^{1}$, L. NUEVAS-PAZ ${ }^{3}$, J. ACOSTA-ESQUIJAROSA ${ }^{1}$, \\ U. J. JAUREGUI ${ }^{4}$, A. M. LASTRE ${ }^{5}$
}

${ }^{1}$ Centro de Ingeniería de Procesos (CIPRO), Facultad de Ingeniería Química, Instituto Superior Politécnico José Antonio Echeverría, Calle 114 No. 11901 e/ 119 y 127, La Habana, Cuba

${ }^{2}$ Centro de Investigación y Desarrollo de Medicamentos (CIDEM), 26 y 51, La Habana, Cuba

${ }^{3}$ Centro Nacional de Genética Médica. Avenida 31 y 146, La Habana, Cuba

${ }^{4}$ Instituto Superior de Tecnologías y Ciencias Aplicadas (InSTEC), Avenida Salvador Allende esquina Luaces, La Habana, Cuba

${ }^{5}$ University of São Paulo, Chemical Engineering Department

E-mail para contato: arlenlastre@gmail.com

\begin{abstract}
Mangiferin is a natural xantone extensively distributed in higher plants showing different pharmacological properties. In the present study, an ultrasonicassisted extraction (UAE) method was evaluated for obtain mangiferin from Mangifera indica L. (c.v Mango Macho) leaves. Differents extraction parameters were optimized using a response surface methodology and the best conditions reached were at $47 \%$ ethanol concentration, a liquid-to-solid ratio 47:1, and an extraction time of $63 \mathrm{~min}$. under ultrasound irradiation of $150 \mathrm{~W}$. In these circumstances, the yield of mangiferin was $24.15 \pm 0.015 \mathrm{mg} / \mathrm{g}$. For first time, was evaluated the ultrasound assited extraction to higher frecuency and the value of the yield reached was $6.38 \pm 0.062 \mathrm{mg} / \mathrm{g}$. Comparison of UAE of mangiferin respect to microwave and aggited tank was realized and the yield obtained by UAE was inferior, however the ultrasonic time was minor respect to conventional extraction technique. The ultrasonic-assisted extraction is an alternative method to use for the extraction of mangiferin from Cuban mangos.
\end{abstract}

\section{INTRODUCTION}

Mangiferin (1,3,6,7-tetrahydroxyxanthone-2-C-ß-D-glucopyranoside) a C-glucosyl xanthone constituted an important phytochemical as different pharmacological properties reported. For these reason a national technology have been developed from stem bark and leaves of Mangifera indica L. at industrial level (Acosta et al., 2013).

Considering the requirements such as shortened extraction time, reduced solvent consumption, elevated pollution prevention and special care for the thermo labile products, others extraction non-conventional methods have development for obtaining pharmacologically active compounds (Bai et al., 2010; Kullu et al., 2013). Ultrasound has been efficaciously used to extract bioactive substances from plants. The improvement on extraction given by the use of ultrasound is accredited to the disruption of the cell walls, decrease of the particle size and the elevation on the mass transfer of the cell contented to the solvent produced by the breakdown of the bubble create 


\section{9 a 22 de outubro de 2014 \\ Florianópolis/SC}

by cavitation. The feasibility of obtain mangiferin via UAE from Mangifera indica (c.v Tainung No. 1) was reported (Zou et al., 2014). The optimal extraction conditions achieved permit obtains a yield of mangiferin of $58.46 \pm 1.27 \mathrm{mg} / \mathrm{g}$ for a power irradiation of $200 \mathrm{~W}$. On the other hand, response surface methodology (RSM) is effective method for study the response of different variables, influenced by many factors and their interactions, which was initially enunciated by Box and Wilson (Rodrígues et al., 2007). This methodology has been succesly employed for optimizing processes on the extraction of polyphenols (Bai et al., 2010).

Following with ours studies relation to improve the extraction of mangiferin for nonconventional extraction technique (Salomón et al., 2014), the objective of this paper is optimized the UAE of mangiferin from Mangifera indica L. c.v "Mango Macho" using the response surface methodology. The effect the some parameters such type of solvent, the ratio of solvents to vegetal material and extraction time over the optimal extraction of mangiferin were investigated. In addition, was evaluated the influence of ultrasound on the extraction efficiency in comparisons to the conventional solvent extraction, microwave assisted extraction and ultrasound using higer power. The last method was evaluated by first time in the obtation of mangiferin from mango.

\section{MATERIALS AND METHODS}

\subsection{Chemicals}

Mangiferin standard was bought in Chinesse (91.23\% purity HPLC). Ethanol was HPLC grade and bought from Merk (Germany). Deionized water was prepared using Milli-Q water purification system.

\subsection{Plant Material}

The leaves of Mangifera indica L. was collected from plants grown in a fruit farm in San Antonio de los Baños, Mayabeque, Cuba and subsequently dried and milled to obtain particles of around 2-3mm.

\subsection{Reflux extraction (RE)}

Powdered Mangifera indica leaves $(10 \mathrm{~g})$ was refluxed in aggitated tank, with $200 \mathrm{~mL}$ of water (Rusakova et al., 1985).

\subsection{Microwave-assisted extraction (MAE)}

The obtation of mangiferin by MAE was realized considering the experimental procedure reported before (Salomón et al., 2014).

\subsection{Ultrasound Assisted Extraction}

The ultrasound-assisted extraction was carried out in equipment (Sakura, China) with an ultrasound power of $150 \mathrm{~W}$ and frequency of $60 \mathrm{~Hz}$, equipped with a digital timer. The temperature was controlled. The mango leaves, previously powder, $(1 \mathrm{~g})$ were placed in capped tube with a suitable amount of extraction solvent, to take accounts the experimental design. The suspensions were immersed in the ultrasound device, and irradiated under the predetermined conditions. 
Experimental Procedure: A rotational central design was employed to ststiscally optimize the operation parameters and evaluated the principal effects, interactions and quadratic effects on the yield of mangiferin extraction by UAE. According to the principle of the experimental design ethanol concentration, time extraction and liquid-solid ratio,were evaluated as independent variables, which have strong influence over mangiferin extraction. The range and center point values of the three independent variables are selected on the basis of preliminary assay. 17 experiments were realized with tree replicates in the central point.

Response surface methodology (RSM) was employed to optimize the UAE of mangiferin from Mangifera indica $L$. The validated of the models was determined by the coefficient of detremination $\left(\mathrm{R}^{2}\right)$ and the Fisher test value (F-value) obtained from the analys of variances (ANOVA) that was generates by the statistical software used. Models and regression coefficients were considered significant when p-values were lower than 0.05 .

\subsection{Ultrasound Assisted Extraction for Frecuency Higher (UAE FH)}

The ultrasound-assisted extraction was carried out in equipment (Meinhardt Ultraschalltechnik) (Germany) with an ultrasound power of $30 \mathrm{~W}$ and $860 \mathrm{kHz}$, equipped with a digital timer. The temperature was controlled.

\subsection{HPLC Analysis}

The determination of mangiferin was attained by high performance liquid chromatography (HPLC) to take account the method developement for ower group (Salomón et al., 2014).

\section{RESULTS AND DISCUSSION}

Figure 1 show the chromatographic profile of the mangiferin obtaining from Mangifera indica $L$. after UAE and standard mangiferin. The retention time, of 7.3min. obtained from the extract agree well with the reference standard, verifying the presence of mangiferin in Mangifera indica $L$. leaves extract.

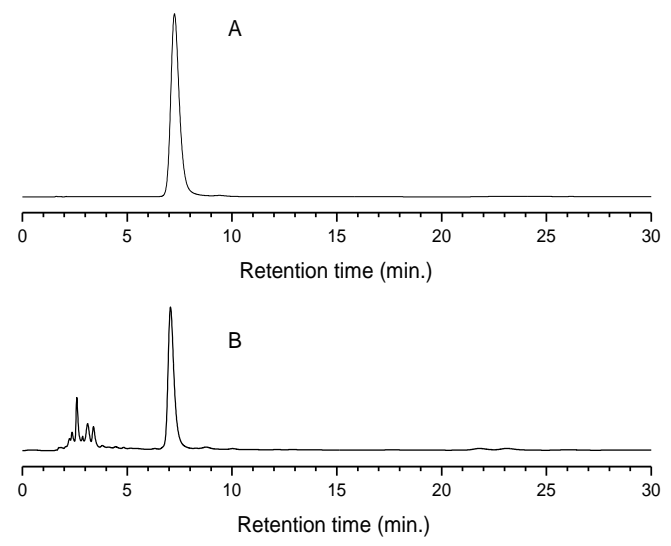

Figure 1 - Chromatogram corresponding to reference standard of mangiferin (A) and extract of mangiferin leaves (B). 


\subsection{Preliminary Study}

Figure 2 shows the results of preliminay studied realized for to know the behaviour of type of solvent, time extraction and liquid-to-solid ratio over the mangiferin yield, expressed in $\mathrm{mg}$ of mangiferin/g of leaves.

Commonly, alcohols and water are used as extraction solvents of phenolic compounds such as mangiferin (Bai et al., 2010). For to evaluated the effect of type of solvents on the yield of mangiferin, the experiments were realized to keeping constant the liquid-to-solid ratio $20: 1(\mathrm{~mL} / \mathrm{g})$ and extraction time, 60min.
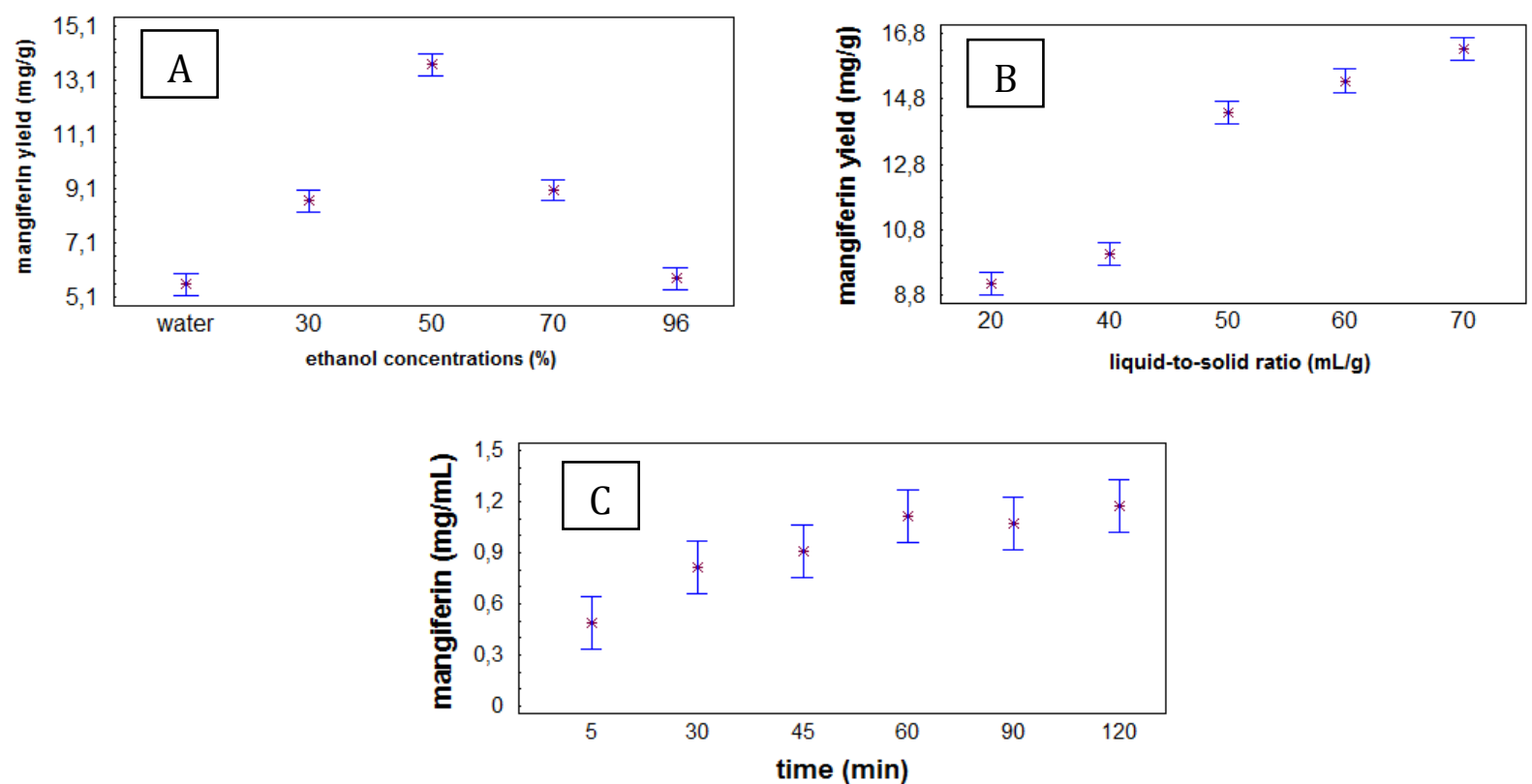

Figure 2 - Effect of parameters over mangiferin extraction. (A) Ethanol Concentrations (B) Liquid-to-Solid Ratio and (C) Extraction time.

As show in the Figure 2a, the extraction of mangiferin improved significantly when the concentration of ethanol increased from 0 to $50 \%$, reaching a maximum value, which was $13.67 \pm$ $0.44 \mathrm{mg} / \mathrm{g}$, at $50 \%$ ethanol, followed by a clear decrease when increase of the ethanol concentration from $50 \%$ to $96 \%$. The results are agreed with other report, where the authors recommend work with an ethanol: water mixture at $40 \%$ (Zou et. al, 2014) in the polyphenols obtaining. The value of mangiferin extracting is $5.58 \pm 0.42 \mathrm{mg} / \mathrm{g}$, using water as solvent. Water is a nontoxic and inexpensive solvent and has widely been used for extraction of bioactive compounds; however its extraction efficiency is always lower than with a mixture of ethanol and water.

The effect of liquid-to-solid ratio was evaluated (Figure 2B) using water as solvent and 60 min. as extraction time. When the liquid-to-solid ratio increased from 10:1 to 70:1, the yield of mangiferin increased. The maximum yield of mangiferin has a value of $16.33 \pm 0.29 \mathrm{mg} / \mathrm{g}$ and was obtained at a liquid-to-solid ratio of 70:1. This behavior is expect due to ultraound extraction is improvement when the quantity of solvent is elevated. Generally, the large liquid ratio can dissolve constituents more effectively, leading to an enhancement of the extraction yield (Li et al., 2005). However, this will cause solvent waste and trouble in the next technological stage, due to 
be necessary, generally, to evaporate for to concentrate the menstruo. On the contrary, a small ratio will result in a lower extraction yield due to be reaching the equilibrium concentrations (Valachovic et al., 2001). Therefore, the choice of a proper solvent volume is significant.

For last, the effect of extraction time was investigated (Figure 2C). The experiments were realized used water as the extraction solvente and a liquid-to-solid ratio of 20:1. The percentage extraction of mangiferin increased with the increase of ultrasonic extraction time. At longer extraction time, the mangiferin extraction was kept constant until 120min. after initiated of experiments. The extraction of mangiferin reached the highest percentage extraction $(1.11 \pm 0.26 \mathrm{mg} / \mathrm{mL}$, in $60 \mathrm{~min}$. The results allow to make a suggestion that the ultrasound energy have the capacity for to accelerate the establishment of an equilibrium between the target compounds and the extraction solvent. These occurs in the half of time respect to stirred tank and is an enormous advantage of ultrasound compared to traditional extraction methods (Salomón et al., 2014).

\subsection{Optimization the mangiferin extraction using a RSM}

The extraction of mangiferin from Mangifera indica L. leaves was further optimized using the RSM approach considering the preliminary results obtained. Table 1 shows the results of the experimental desing. The yields of mangiferin are in the ranged from 9.35 to $24.05 \mathrm{mg} / \mathrm{g}$. Report previous show a yield of extract mangiferin of $58.46 \pm 1.27 \mathrm{mg} / \mathrm{g}$ used an ethanol concentration of $40 \%$, in $20 \mathrm{~min}$. of extraction time (Zou et. al, 2014). Probably the dissimilarities finding in the value of mangiferin extracting are due to differences in the variety of mangos studied and variances in the selection of the values of extraction parameters. The maximum mangiferin yield was verified under the experimental conditions of extraction time $60 \mathrm{~min}$., ethanol concentration $45 \%$ and liquid / solid ratio of 45 .

By applying multiple regression analysis to the experimental data, the response variable and the considered variables are correlated by the following second-order polynomial Equation (1):

$$
\text { yield }=23.83+0.5 x_{1}+1.34 x_{2}+0.56 x_{3}-3.6 x_{1}^{2}-2.35 x_{2}^{2}-4.03 x_{3}^{2}
$$

The analysis of variance (ANOVA) of the quadratic regression model exhibited that the values of the determination coefficient $\left(\mathrm{R}^{2}\right)$ and th eadjusted determination coefficient (Adj. $\mathrm{R}^{2}$ ) were 0.83 and $0.73 \%$, respectively, which suggested that a high degree of correlation between the observed and predicted values. The $\mathrm{p}$ values are used to check the significance of each coefficient. The results showed that the quadratic terms are the significance. The most significants quadratic factor, which influenced the mangiferin yield were ethanol concentration and the time followed by ratio of solvent to raw material.

Figure 3 shows the three-dimensional response surface plots and their respective contour plots. As can observed in the figure an increase of time $\left(\mathrm{X}_{1}\right)$, liquid-to-solid ratio $\left(\mathrm{X}_{2}\right)$ and ethanol concentration $\left(\mathrm{X}_{3}\right)$ results in an initial increase of mangiferin yield to a maximum until level certain that then decreases as the concentration, the ratio and time continue to increase. 
Table 1 - Results obtained from the UAE tests. Experimental rotational central design

\begin{tabular}{|c|c|c|c|c|}
\hline Experiment & $\begin{array}{c}\left(\mathbf{X}_{\mathbf{1}}\right) \\
\text { Time (min.) }\end{array}$ & $\begin{array}{c}\left.\mathbf{( X}_{\mathbf{2}}\right) \\
\text { Solvent volume/vegetal } \\
\text { material ration }(\mathbf{m L} / \mathbf{g})\end{array}$ & $\begin{array}{c}\left.\mathbf{X}_{\mathbf{3}}\right) \\
\text { Ethanol } \\
\text { concentration } \\
(\mathbf{\%})\end{array}$ & $\begin{array}{c}\text { Mangiferin } \\
\text { yield } \\
\text { (mgMF/g } \\
\text { leaves) }\end{array}$ \\
\hline 1 & 60 & 45 & 90 & 11.60 \\
\hline 2 & 30 & 30 & 70 & 15.77 \\
\hline 3 & 30 & 60 & 20 & 16.82 \\
\hline 4 & 60 & 45 & 45 & 24.05 \\
\hline 5 & 90 & 60 & 20 & 17.55 \\
\hline 6 & 60 & 70 & 45 & 16.50 \\
\hline 7 & 90 & 60 & 70 & 17.91 \\
\hline 8 & 60 & 45 & 45 & 24.02 \\
\hline 9 & 60 & 45 & 0 & 9.59 \\
\hline 10 & 110 & 45 & 75 & 14.28 \\
\hline 11 & 30 & 60 & 45 & 15.43 \\
\hline 12 & 10 & 45 & 20 & 9.35 \\
\hline 13 & 90 & 30 & 45 & 10.80 \\
\hline 14 & 60 & 45 & 20 & 24.04 \\
\hline 15 & 30 & 30 & 70 & 13.2 \\
\hline 16 & 90 & 30 & 45 & 13.52 \\
\hline 17 & 60 & 20 & & \\
\hline
\end{tabular}

The behaviour obtained indicates that, due to the extraction time prolongs the chemical decomposition of mangiferin may occur. Even if ultrasound-assisted extraction has considerable potential in extraction fields of natural constituents, composition of some edible fruits is deteriorated after ultrasound treatment (Zhao et al., 2012). Therefore, it is importante to research and to examine the mechanism of ultrasonic degradation of mangiferin and other compounds presents in Mangifera indica.

The decreased yield when the liquid-to-solid ratio increased can be explained by the increasing part of water absorbed in the rehydrated leaves, which represent the mass of dry leaves. This loss of extract trapped in the matrix explains the decrease in yield for higher S/L ratio due to disminished the solubility. Similar results are reported before this study (Petigny et al., 2013).

With respect to the tendency obtained for the parameter ethanol concentrations, it is know that the polyphenols yield reached maximum when ethanol concentration is near to $50 \%$, while either too high or too low degree will disminushed the yield (Kullu et al, 2013). This can be explain because the mangiferin presents in Mangifera indica is a xantona (polyphenols) with moderate polarity and ethanol at $50 \%$ may contribute to the extraction of this.

The optimal values of the selected variables were obtained by solving the regression equation were $47 \%$ ethanol, a liquid-to solid ratio of 47:1, and an extraction time of $63 \mathrm{~min}$., with the corresponding value of yield of mangiferin of $24.15 \pm 0.015 \mathrm{mg} / \mathrm{g}$. 


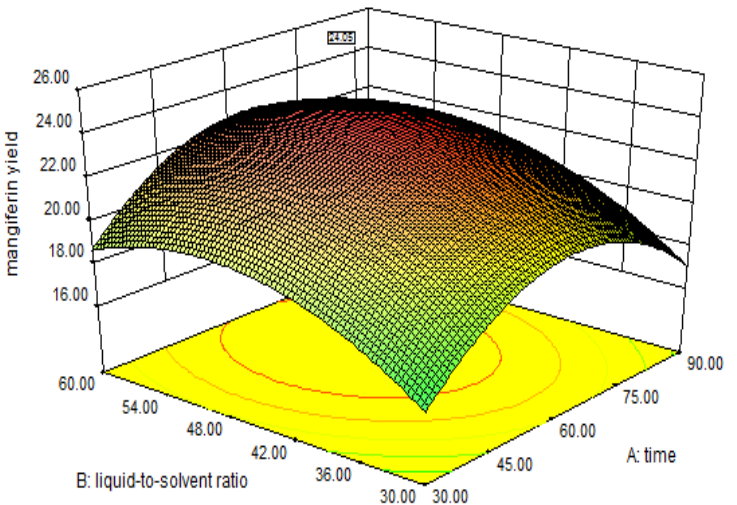

A

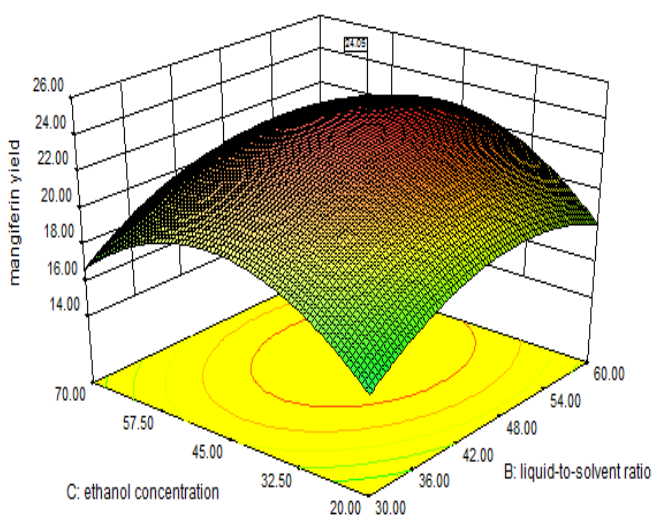

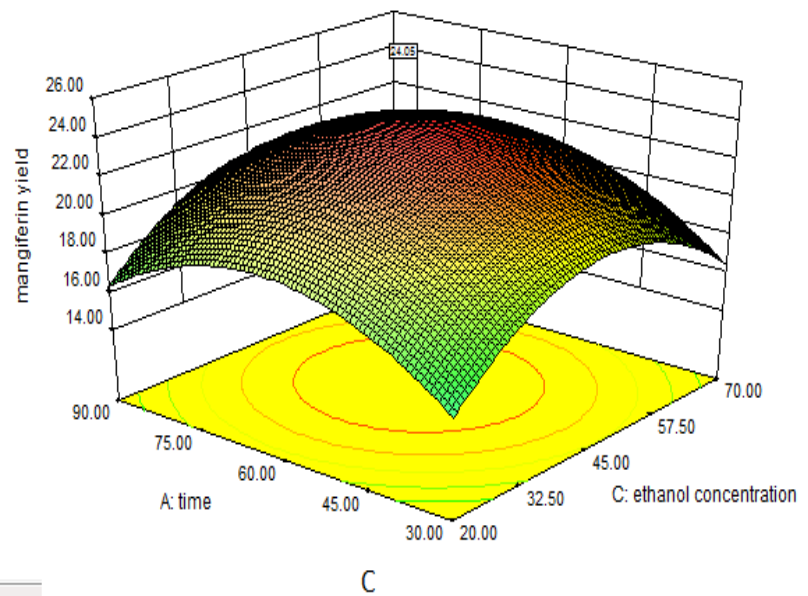

Figure 3 - Response surface and contour plots of mangiferin extraction from mango leaves by

UAE. (A) time $\left(\mathrm{X}_{1}\right)$ and liquid-to-solid ratio $\left(\mathrm{X}_{2}\right)$; (B) liquid-to-solid ratio $\left(\mathrm{X}_{2}\right)$ and ethanol concentration $\left(\mathrm{X}_{3}\right)$; and $(\mathrm{C})$ time $\left(\mathrm{X}_{1}\right)$ and ethanol concentration $\left(\mathrm{X}_{3}\right)$.

\subsection{Comparison of UAE, UAE FH, MAE and conventional extraction technique}

The values of mangiferin yield were determined using water as solvents with the objective to compare all methods. Similar percentage of extraction $18.9 \pm 0.40$ and $18.3 \pm 1.5 \mathrm{mg} / \mathrm{g}$ were reached when MAE and stirred tank were used respectively (Table 2).

Table 2 - Comparison of diferentes methods for mangiferin extraction

\begin{tabular}{ccccc}
\hline Parameters & \multicolumn{4}{c}{ Type of Extraction } \\
\cline { 2 - 5 } & RE & MAE & UAE & UAE FH \\
\hline Water/S ration $(\mathrm{mL} / \mathrm{g})$ & 20 & 10 & 45 & 20 \\
Extraction time $(\mathrm{min})$ & 120 & 5 & 60 & 5 \\
Yield $(\mathrm{mg} \mathrm{MF} / \mathrm{g}) \pm \mathrm{SD}$ & $18.9 \pm 0.40$ & $18.3 \pm 1.5$ & $9.59 \pm 0.015$ & $6.38 \pm 0.062$ \\
\hline
\end{tabular}


UAE can obviously reduce the extraction time respect to aggited tank but the yield reached is minor $(9.59 \pm 0.015 \mathrm{mg} / \mathrm{g})$. The results showed that the UAE FH technique provided inferior results respect to all studied methods. It is well known, under the powerful ultrasound the cavitation occurring in water, yields hydroxyl radicals which lead to chemical decomposition. However is necessary to evaluate the mechanism of ultrasonic degradation of mangiferin due to not find report previuos and this way can to explain the phenomenon observed.

\section{CONCLUSIONS}

The feasibility to used ultrasound-assisted extraction method for to obtain mangiferin from Mangifera indica L. c.v. Mango Macho was show in this paper. The optimal extracting conditions and mangiferin a yield was defined using RSM technique and is described as follows: ultrasound time of $63 \mathrm{~min}$., ethanol concentration of $47 \%$ and liquid to solid relation of 47 . In this condition, the maximum mangiferin content was $24.15 \pm 0.015 \mathrm{mg} / \mathrm{g}$. Comparison of UAE respect to MAE and stirred tank show that the yield of mangiferin obtained is minor whit values of $18.9 \pm 0.40$ and $18.3 \pm 1.5 \mathrm{mg} / \mathrm{g}$ for RE and MAE respect to $9.59 \pm 0.015 \mathrm{mg} / \mathrm{g}$ obtained for UAE. However the time compsummtion for UAE is the half respect to a conventional method. The preliminar study of UAE FH for to obatin mangiferin was realized by firts time. The results obtained could be optimized.

\section{REFERENCES}

ACOSTA, J. et al. Procedimiento de obtención de Mangiferina a partir de hojas y corteza de Mangifera indica Linn. Applied Patent OCPI Application Number CU/P/2013/123, Havana, Cuba, 2013.

BAI, X.L. et al. Optimization of microwave-assisted extraction of polyphenols from apple pomace using response surface methodology and HPLC analysis. J. Sep. Sci., v. 33, p. 37513758, 2010.

KULLU, J. et al. Experimental and modeling studies on microwave-assisted extraction of mangiferin from Curcuma amada. Biotech., v. 4, p. 107-120, 2013.

LI, H. et al. Application of ultrasonic technique for extracting chlorogenic acid from Eucommia ulmodies Oliv. (E. ulmodies). Ultrason. Sonochem., v. 12, p. 295-300, 2005.

PETIGNY, L. et al. Batch and Continuous Ultrasound Assisted Extraction of Boldo Leaves (Peumus boldus Mol.). Int. J. Mol. Sci., v. 14, p. 5750-5764, 2013.

RODRIGUES, S. et al. Ultrasound extraction of phenolic compounds from coconut (Cocos nucifera) shell powder. J. Food Eng., v. 80, p. 869-872, 2007.

RUSAKOVA, S. et al. Process for preparing mangiferin. Patente FR2486941, 1985.

SALOMON, S. et al. Experimental studies on microwave-assisted extraction of mangiferin from Mangifera indica L. leaves. Emir. J. Food Agri., v. 23, p. 458-464, 2014.

VALACHOVIC, P. et al. Towards the industrial production of medicinal tincture by ultrasound assisted extraction. Ultrason. Sonochem., v. 8, p. 111-117, 2001.

ZHAO, L. Ch. et al. Ultrasound-Assisted Extraction of Syringin from the Bark of Ilex rotunda Thumb Using Response Surface Methodology. Int. J. Mol. Sci., v. 13, p. 7607-7616, 2012. 